\title{
АДМИНИСТРАТИВНО-ПРАВОВОЕ РЕГУЛИРОВАНИЕ ЭКОНОМИЧЕСКОЙ ДЕЯТЕЛЬНОСТИ ТАМОЖЕННЫХ ОРГАНОВ
}

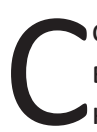
оциально-экономическое развитие России на современном этапе происходит на фоне расширения сферы предпринимательства с одной стороны и твердого воздействия государства на все сферы общественной жизни с другой. Несмотря на очевидные преимущества рыночного пути развития, остается высокой доля влияния государства на происходящие в обществе социально-экономические процессы. Без государственного вмешательства в экономику невозможно обеспечить гарантии прав и свобод человека и гражданина, закрепленные в Конституции Российской Федерации. В силу требований Конституции РФ, государство обязано создавать социально-экономические рычаги, влияющие на повышение уровня и благосостояния каждого гражданина, поддерживать социально незащищенные и малоимущие слои населения, накапливать материальные ресурсы для выполнения своих основных задач и функций.

В условиях современного развития общество не может отказаться от вмешательства в экономику, от государственно-правового регулирования экономикой. Профессор В.Ф. Яковлев пишет: «Внедряя начала саморегулирования, государство, разумеется, уменьшает свою роль в экономике. Но оно не может самоустраниться от нее. Самоустранение государства может привести к печальным, а иногда даже и к гибельным последствиям» ${ }^{1}$. Без воздействия на экономику не об-

1 Яковлев В.Ф. Гражданский кодекс и государство//Вестник ВАС РФ, 1997. № 6. С. 133. ходится ни одно из развитых государств. Различаются лишь пределы и формы государственного вмешательства в экономику.

Современное состояние и развитие экономических отношений в России, говорит о том, что роль государства в экономике не может быть нивелирована. Это связано с рядом крупных диспропорций в развитии России: демографический кризис; высокая динамика потребления; низкая конкурентоспособность продукции российской промышленности; социальная нестабильность (рост объема денежных доходов у 10 процентов наиболее обеспеченных граждан при неизменности объема доходов у 10 процентов наименее обеспеченных); сохранение финансовой системы унитарного государства при развитии федерализма в России; направленность иностранных инвестиций преимущественно в одну область экономики - сырьевую.

Термин «управление» происходит от латинского слова administratio. Управлять - значит направлять, руководить, организовывать людей, общество, происходящие в нем процессы и др. В управлении находят свое непосредственное выражение его функции, определяемые природой и назначением управленческой деятельности: регулирование, координация, регламентация, организация, прогнозирование, планирование, надзор, контроль, мониторинг и др. Регулирование - это административно-правовая функция управления, обеспечивающая равновесное состояние институциональных образований экономической системы, выполнение политических, социальных, эко- 
номических и других основных задач внутреннего и внешнего значения.

На разных этапах развития общества и при разных условиях его развития цель и задачи государственного регулирования экономикой могут быть разными. В настоящий период развития государственности цель государственного регулирования экономикой носит двоякий характер. С одной стороны - это обеспечение публичных интересов: оборона и безопасность государства, выход страны на международное экономическое пространство, сбалансированное развитие всех регионов. С другой - реализация частных интересов: обеспечение прав и свобод человека и гражданина, защита социально уязвимых слоев населения, развитие малого и среднего бизнеса и др..

Административно-правовое регулирование может быть определено как регламентированная нормами права деятельность наделенных властными полномочиями публичных субъектов. В управлении экономикой принимают участие различные органы исполнительной власти. На федеральном уровне это: Правительство Российской Федерации, Министерство промышленности и торговли Российской Федерации, Министерство регионального развития Российской Федерации, Министерство финансов Российской Федерации, Министерство экономического развития Российской Федерации, а также федеральные службы: Федеральная таможенная служба, Федеральная налоговая служба и др. От координации их действий зависит успех экономической политики государства.

Большая роль в реализации социально-экономической политики государства отводится Таможенным органам России. Таможенные органы - составляют единую федеральную централизованную систему. Федеральный закон от 27 ноября 2010 № 311-Ф3 «О таможенном регулировании в Российской Федерации» законодательно закрепил систему таможенных органов Согласно положений статьи 10 Закона № 311-Ф3 систему таможенных органов составляют ${ }^{2}$ : федеральный орган исполнительной власти, уполномоченный в области таможенного дела - Федеральная таможенная служба (ФТС России); региональные таможенные управления; таможни; таможенные посты.

Одним из наиболее важных критериев эффективности деятельности ФТС России является выполнение установленных прогнозных показателей по наполнению доходной части федерального бюджета. В 2012 году таможенными органами в федеральный бюджет

2 Собрание законодательства, 2010. - № 48. - Ст. 6252. перечислено 6 581,04 млрд. рублей, что более чем на 10 \% превышает аналогичный показатель 2011 года 3 .

Таможенные платежи, администрируемые ФТС России, составляют более половины поступлений федерального бюджета. В 2012 году их доля в бюджете Российской Федерации составила 50,5 \%, что почти на $10 \%$ превысило аналогичный показатель поступлений налоговых платежей, входящих в систему налогов и сборов и администрируемых налоговыми органами России ${ }^{4}$.

Структура платежей в 2012 году, как и в предыдущий год, характеризуется высокой долей экспортной составляющей. Доля платежей, взимаемых при экспорте товаров, составила 62,3\% (в 2011 году - 62,4\%), что указывает на продолжающееся усиление экспортной зависимости экономики России ${ }^{5}$.

Экономическая деятельность таможенных органов не реализуется сама по себе. Она всегда воплощается в конкретные действия, формы, методы, отражающие содержание и специфику этой деятельности. Применительно к деятельности таможенных органов форма является способом выражения государственно-правового содержания деятельности таможенных органов, т.е. всех тех качеств (прежде всего юридических), которые характеризуют ее как специфический орган власти. Руководство деятельностью ФТС России осуществляет Правительство Российской Федерации. Правительство РФ наделило таможенные органы полномочиями по выработке государственной политики и нормативному правовому регулированию, контролю и надзору в области таможенного дела.

Правовая форма управленческой деятельности таможенных органов существенно отличается от других правовых форм их деятельности тем, что посредством правовых форм практически организуется осуществление задач и функций таможенных органов; повседневное практическое руководство деятельностью органов, входящих в систему (региональных таможенных управлений (РТУ), таможенных постов (ТП), таможен), регулирование, контроль и другие функции на основе и во исполнение законов.

3 Таможенная служба Российской Федерации в 2012 - 2013 г: справочные материалы к заседанию коллегии// Федеральная таможенная служба: сайт. URL :http://www.customs.ru

4 В 2012 году в Федеральный бюджет поступило 12845,49 млрд. рублей, из них привлечено: ФТС - 6 581,04 млрд. рублей $(50,5 \%)$;

ФНС - 5 160,12 млрд. рублей (40,2 \%).

5 Cм. http://www.customs.ru 
Хотелось бы обратить внимание на то, что в соответствии с положениями пункта 1 статьи 2 Федерального закона № 311-Ф3 «О таможенном регулировании в Российской Федерации» таможенное регулирование в Российской Федерации в соответствии с таможенным законодательством Таможенного союза и законодательством Российской Федерации представляет собой совокупность средств и методов обеспечения соблюдения мер таможенно-тарифного регулирования, а также запретов и ограничений при ввозе товаров в Российскую Федерацию и вывозе товаров из Российской Федерации.

Характерные черты правовых форм деятельности таможенных органов наиболее отчетливо проявляются в государственно-властных, исполнительно-распорядительных, организационно-направленных, контрольных действиях.

Формы экономической деятельности таможенных органов в силу их направленности весьма многообразны. Выбор в конкретной ситуации тех или иных форм зависит от многих обстоятельств. На содержание принимаемого управленческого решения в экономической деятельности могут оказывать влияние следующие факторы: характер компетенции органа (РТУ, ТП, таможни) или должностного лица, принимающего решение (осуществляющего закрепленные по его должности действия); уровень правовой регламентации между субъектами; суббординация субъекта; характер управленческих связей (прямое или оперативное управление); особенности управляющего воздействия; внутренне или внешнее взаимодействие; конкретные цели совершаемой экономической деятельности; характер решаемых в процессе экономической деятельности вопросов; характер вызываемых данными действиями последствий и т.п.

Bсе используемые таможенными органами и их должностными лицами формы при осуществлении экономической деятельности подчинены главной целям деятельности ФТС России. Поэтому они избираются ФТС и органами, входящими в ее структуру непроизвольно. Как правило, формы деятельности государственных органов регламентируются административно-правовыми нормами (например, в актах, касающихся правового положения того или иного органа управления, в должностных инструкциях, регламентах). Формы деятельности таможенных органов, в том числе экономической деятельности регламентируются не только российскими административно-правовыми актами, но и административно-правовыми нормами международного значения, например, административным договором - Таможенным кодексом таможенного союза, принятым
Решением Межгосударственного Совета ЕврАзЭС на уровне глав государств.

Выбор конкретной формы деятельности таможенных органов подчинен определенным закономерностям, а также назначению и функциям деятельности (в частности экономической); содержанию и характеру разрешаемых вопросов; направлениям; целям воздействия; особенностям конкретного объекта и др.

Большинство теоретиков административного права все формы управленческой деятельности разделяют на правовые и организационные (неправовые). Известно, что правовые формы влекут за собой наступление юридических последствий в виде возникновения, изменения или прекращения административно-правовых отношений в экономической деятельности таможенных органов.

Bсе разнообразие правовых форм экономической деятельности таможенных органов можно классифицировать по следующим основаниям:

По содержанию: правотворческая (определение направлений таможенной политики, выработка правовых норм - издание нормативных (подзаконных) актов таможенных органов (распоряжений, приказов), правовых актов, регламентирующих толкование правовой нормы (например, инструкций о порядке исчисления таможенных пошлин, порядке заполнения деклараций и др.); правоприменительная (выявление правонарушений, пресечение контрабанды, защита таможенной границы, обеспечение экономической безопасности государства и др.).

Акты управления таможенных органов, направлены на экономическую деятельность таможенных органов и предназначены регулировать общественные отношения в установленной сфере деятельности или решать конкретное управленческое дело, а также определять персональное поведение субъекта (адресата). Под актом управления таможенных органов понимается имеющее подзаконный характер одностороннее, юридически властное предписание, издаваемое в рамках полномочий таможенного органа (ФТС России, РТУ, ТП, таможни) или должностным лицом с обязательным соблюдением установленных прочедур.

По целям: внутренние (подбор кадров, обучение, аттестация, делопроизводство, управление внутри организационной структуры); внешние (выполнение возложенных на орган задач и функций).

По способу выражения: словесные (письменные и устные); конклюдентные.

Правовые формы всегда влекут за собой четко выраженные юридические последствия, а потому они и в максимальной степени претендуют на обозначе- 
ние их в качестве административно-правовых форм. Например, межправительственными и межгосударственными административно-правовыми актами (договорами) регулируются особенности зачисления и распределения ввозной таможенной пошлины6, таможенные процедуры ${ }^{7}$, приказами ФТС России регулируются особенности заполнения таможенных деклараций ${ }^{8}$ и др.

Следует заметить, что заключение административных договоров между равными администраторами (например, таможенными органами двух или нескольких государств, таможенными органами и налоговыми органами и др.) есть одна из важнейших правовых форм управления.

Административный договор - это основанный на административно-правовых нормах и выработанный в результате добровольного соглашения воли двух (и более) субъектов права (одним из которых всегда выступает представитель государства) управленческий акт, устанавливающий, изменяющий или прекращающий порядок правоотношений в определенной сфере, и конкретизирующий объем полномочий и ответственности участников.

К административным договорам относят:

- договоры о разграничении компетенции (например, в вопросах разграничения компетенции и предметов ведения между ФТС России иными исполнительными органами):

6 См. Соглашение между Правительством РФ, Правительством Республики Беларусь, Правительством Республики Казахстан от 20 мая 2010 «Об установлении и применении в таможенном союзе порядка зачисления и распределения ввозных таможенных пошлин (иных пошлин, налогов и сборов, имеющих эквивалентное действие)»; См. также Решение Комиссии Таможенного союза от 25 марта 2010 № 199 «О механизме зачисления и распределения ввозных таможенных пошлин (иных пошлин, налогов и сборов, имеющих эквивалентное действие)» и др./ Режим доступа СПС КонсультантПлюс;

7 Решение Комиссии Таможенного союза от 20 мая 2010 № 329 «О перечне категорий товаров, в отношении которых может быть установлена специальная таможенная процедура и условиях помещения товаров под такую таможенную процедуру» / Режим доступа СПС КонсультантПлюс;

8 См. например, Приказ ФТС РФ от 04 февраля 2011 № 206 «Об утверждении Инструкции об особенностях заполнения заявления на условный выпуск (заявления на выпуск компонента вывозимого товара) и декларации на товар»; Приказ ФТС РФ от 12июля 2010 № 1315 «Об условном выпуске товаров, ввозимых в качестве вклада в уставные (складочные) капиталы организаций» и др. / Режим доступа СПС КонсультантПлюс;
- договоры о взаимодействии, сотрудничестве, обмене информацией (например, «О функционировании государственной информационной системы «Правоохранительный портал Российской Федерации» ${ }^{9}$ и др.;

- договоры об охране;

- контракты с государственными служащими и др.

К правовым формам управления относят также лицензирование и мониторинг. Лицензия - специальное разрешение на право осуществления юридическим лицом или индивидуальным предпринимателем конкретного вида деятельности, которое подтверждается документом, выданным лицензирующим органом на бумажном носителе или в форме электронного документа ${ }^{10}$. Лицензирование видов деятельности осуществляют специально уполномоченные государством органы, перечень которых закреплен Постановлением Правительства от 21 ноября 2011 № $957^{11}$.

Таможенные органы не входят в указанный перечень. Однако, деятельность, например, таможенных перевозчиков подлежит лицензированию. При проведении отдельных таможенных процедур таможенные органы вправе требовать предоставление лицензии. Так, выпуск товаров осуществляется таможенными органами при соблюдении следующих условий: таможенному органу представлены лицензии, сертификаты, разрешения и (или) иные документы, необходимые для выпуска товаров в соответствии с ТКТС и (или) иными международными договорами государств членов таможенного союза ${ }^{12}$.

Мониторинг - (от лат. monitor - напоминающий, надзирающий) - непрерывное наблюдение за экономическими объектами, анализ их деятельности как составная часть управления13. Таможенные органы

9 Приказ Минэкономразвития РФ № 412, МВД РФ № 645, Министра обороны РФ № 1183, Минюста РФ № 216, МЧС РФ № 422, Минздравсоцразвития РФ № 782Н, Минкомсвязи РФ № 120, ФСБ РФ № 425, ФСКН РФ № 370, ФТС РФ № 1638, ФМС РФ № 264, ФНС РФ № ММВ-7-6/437@ от 03 сентября 2010/ Режим доступа СПС КонсультантПлюс;

10 Федеральный закон от 04 мая 2011 № 99-Ф3 «О лицензировании отдельных видов деятельности»// СЗРФ, 2011. - № 19. -Ст. 2716;

11 Об организации лицензирования отдельных видов деятельности// С3 РФ, 2011. - № 48. -Ст. 6931;

12 См. пункт 1 статьи 195 ТК ТС;

13 См. Райзберг Б.А., Лозовский Л.Ш., Стародубцева Е.Б. Современный экономический словарь. М.: ИНФРА-М, 2006; 
в соответствии с Законом 311-ФЗ уполномочены осуществлять мониторинг деятельности экономических операторов в части соблюдения уполномоченным экономическим оператором условий присвоения такого статуса ${ }^{14}$.

Организационные формы управленческой деятельности (их часто называют неправовые) не влекут за собой наступление юридических последствий, однако являются весьма распространенными и совершаются на основе и во исполнение правовых предписаний. В области экономической деятельности таможенных органов к ним можно отнести:

- проведение организационных мероприятий: инструктирование сотрудников; совещания; разработка наглядной информации для субъектов таможенных правоотношений; консультирование; изучение, обобщение и распространение положительного опыта работы; разработка мероприятий по проведению таможенного контроля; и др.

- сбор и обработка информации (например, для АИС таможенных органов;

- осуществление материально-технических работ (например, составление различных справок, отчетов, делопроизводство, оформление документов). Посредством осуществления технических операций обслуживается сам процесс управления.

Формы экономической деятельности таможенных органов непосредственным образом связаны с методами правового регулирования и выражаются через них. Методы - это совокупность приемов и способов, а также средств, которые применяются для успешного решения стоящих перед Таможенными органами задач, позволяющие применять наиболее эффективные средства воздействия органа исполнительной власти (должностных лиц) на управляемые объекты. Методы экономической деятельности таможенных органов весьма разнообразны. Но это не исключает возможности определенным образом типизировать их в интересах выявления присущих им наиболее значимых свойств и специфических черт.

Главным содержанием в сущностной характеристике методов экономической деятельности таможенных органов является их целенаправленное назначение. В целом для методов экономической деятельности та-

14 См. статья 94 Федерального закона от 27 ноября 2010 № 311-Ф3 «О таможенном регулировании в Российской Федерации»; моженных органов наиболее характерными являются следующие черты:

- $\quad$ их органическая связь с целевым назначением этого вида деятельности;

- выражают управляющее (упорядочивающее) воздействие на отношения в установленной сфере деятельности;

- имеют юридически-властный характер;

- используются таможенными органами в качестве средств реализации закрепленной за ними компетенции;

- направлены на конкретного адресата и не могут быть обезличенными.

- в методах экономической деятельности таможенных органов в соответствующем объеме находит свое выражение государственный (публичный) интерес, воля государства и др.

Для методов экономической деятельности таможенных органов характерна правовая форма их непосредственного практического выражения. Свое наиболее ощутимое проявление они получают в правовых актах таможенных органов. Выбор конкретных методов экономической деятельности таможенных органов находится в прямой зависимости не только от особенностей организационно-правового статуса субъекта - РГУ, ТП, таможни, но и от особенностей объекта воздействия (например, статуса объекта, формы собственности и т.п.).

В соответствии с Постановлением Правительства от 26 июля 2006 г № 459 ФТС России в области экономической деятельности применяет следующие методы:

- осуществляет контроль и надзор в области таможенного дела, а также функции агента валютного контроля, функции по проведению транспортного контроля в пунктах пропуска через государственную границу Российской Федерации и санитарно-карантинного, карантинного фитосанитарного и ветеринарного контроля и др.;

- определяет порядок ведения реестров лиц, осуществляющих деятельность в области таможенного дела, а также порядок ведения реестра банков, иных кредитных и страховых организаций, банковские гарантии которых принимаются таможенными органами в качестве обеспечения уплаты таможенных платежей;

- совместно с Министерством финансов Российской Федерации определяет порядок контроля таможенной стоимости товаров;

- $\quad$ разрабатывает форму и порядок принятия предварительных решений о классификации товаров в соответствии с Товарной номенкла- 
турой внешнеэкономической деятельности в отношении конкретного товара, о стране происхождения товара;

- разрабатывает и утверждает порядок и технологии производства таможенного оформления в зависимости от видов товаров, перемещаемых через таможенную границу, вида транспорта, используемого для такого перемещения, категорий лиц, перемещающих товары и транспортные средства;

- ведет таможенную статистику;

- информирует и консультирует;

- осуществляет ведение товарных номенклатур внешнеэкономической деятельности;

- организует проведение необходимых исследований, испытаний, экспертиз, анализов и оценок, а также научных исследований в установленной сфере деятельности и многое другое ${ }^{15}$

Наиболее распространенным методом экономической деятельности таможенных органов является контроль и надзор.

Контроль (от франц. controle - проверка) - составная часть экономической деятельности таможенных органов, заключающаяся в проверке соответствия действий субъектов таможенных правоотношений необходимому состоянию, предусмотренному законами, положениями, инструкциями, другими нормативными актами, а также международными договорами, проектами, соглашениями.

Контрольная функция государства присуща всем органам государственной власти в пределах закрепленной за ними компетенции. Государственный контроль в сфере экономической деятельности по правилу, установленному в Бюджетном кодексе РФ, обеспечивается бюджетными средствами, формируемыми за счет налогов и сборов либо доходов, получаемых посредством оказания публичных услуг.

Надзор как составная часть экономической деятельности таможенных органов, представляет собой разновидность контроля, в котором преобладают наблюдательные функции. Особенностью надзорной деятельности ФТС России является то, что надзор осуществляется не только за декларантами, но и в порядке иерархической подчиненности (за деятельностью РТУ, ТП, таможен и их должностных лиц).

Важно заметить, что в соответствии со ст. 76 ТК ТС таможенные пошлины, налоги исчисляются пла-

15 См. например, Постановление Правительства РФ от 26 июля 2006 № 459 «О Федеральной таможенной службе»// С3 РФ. - 2006. - № 32. -Ст. 3569. тельщиками таможенных пошлин, налогов самостоятельно, за исключением случаев, установленных международными договорами государств - членов таможенного союза. Плательщиками таможенных пошлин, налогов являются декларант или иные лица, на которых в соответствии с настоящим Кодексом, международными договорами государств - членов таможенного союза и (или) законодательством государств - членов таможенного союза возложена обязанность по уплате таможенных пошлин, налогов ${ }^{16}$. Таможенные органы организуют мероприятия по проведению контроля за всесторонним и полным поступлением таможенных пошлин и налогов в бюджет государства.

Средства и методы реализации задач и функций, применяемые таможенными органами в экономической деятельности, весьма разнообразны. Это дает основание для их классификации. С общетеоретических позиций выделяют два универсальных метода - убеждение и принуждение, которые проявляются как два взаимосвязанные полюсы единого механизма обеспечения должного поведения и правопорядка в таможенном деле. Под содержанием убеждения и принуждения следует понимать систему средств, в которых конкретизируют государственное управляющее воздействие в целях обеспечения должного или возможного поведения субъектов таможенных правоотношений.

Убеждение призвано оказать первоочередное влияние на волю и сознание субъектов отношений. Убеждение в области таможенного дела есть совокупность приемов, способов и средств, формирующих сознание и волю участников внешнеэкономических отношений. Средства убеждения, применяемые таможенными органами, основываются на духовных и нравственных ценностях общества, понятии долга, правосознании, правовой культуре. Такие средства убеждения состоят из комплекса мер, направленных на проведение разъяснений, внушений, обмен опытом, формирование интереса, напоминаний (об уплате платежей, об исполнении обязанностей участников внешнеэкономических отношений) и др. В экономической деятельности таможенных органов могут использоваться такие средства как пропаганда, критика, обучение, разъяснение, консультирование, толкование нормативных правовых актов и др.

K сожалению, на практике убеждение далеко не всегда оказывается достаточным средством должного воздействия в отношении отдельных лиц. Поэтому убеждение не исключает применение мер принуж-

16 См. статья 79 ТК ТС. 
дения, которые устанавливает государство, защищая права и свободы своих граждан, экономические интересы общества и т.п. Принуждение есть метод административно-правового воздействия на действия физического или юридического лица в рамках требований закона. Таможенные органы России применяют принуждение в борьбе с контрабандой, при защите таможенной границы Таможенного союза, поддержании правопорядка и т.п. Принуждение используется в целях искоренения деликтности в области таможенного дела, обеспечения экономической безопасности государства, защиты государственного суверенитета и др. К средствам принуждения, которые применяют таможенные органы России в своей профессиональной деятельности относят: административно-предупредительные меры (меры предупреждения деликтности); меры административного пресечения; меры юридической ответственности (наказания).

В экономической деятельности таможенных органов для целей предупреждения и пресечения правонарушений в соответствии с положениями пункта 2 и 3 статьи 2 Федерального закона № 311-Ф3 «О таможенном регулировании в Российской Федерации» применяются меры таможенно-тарифного регулирования, запреты и ограничения, затрагивающие внешнюю торговлю товарами, предусмотренные международными договорами, составляющими договорно-правовую базу Таможенного союза, и принимаемыми в соответствии с указанными договорами актами органов Таможенного союза. В случаях и порядке, которые предусмотрены международными договорами, составляющими договорно-правовую базу Таможенного союза, актами органов Таможенного союза, Российская Федерация применяет отдельные меры таможенно-тарифного регулирования, запреты и ограничения в одностороннем порядке в соответствии с законодательством Российской Федерации. Важным средством предупреждения и пресечения правонарушений в таможенной сфере является контроль, проводимый таможенными органами в области таможенного дела, валютный, транспортный, контроль в пунктах пропуска через государственную границу Российской Феде- рации, санитарно-карантинный и др.

Административное принуждение может использоваться в отношении широкого круга субъектов в области таможенного дела (при этом нельзя сказать «неограниченного», поскольку определенные законом рамки имеются). Важной особенностью является то, что административное принуждение применяется таможенными органами не только к физическим лицам (гражданам России, иностранным гражданам и лицам без гражданства), но и в отношении юридических лиц. Процессуальный порядок его применения отличается оперативностью, относительной простотой и экономичностью.

Среди мер наказания за правонарушения в области таможенного дела Таможенные органы применяют такие как: предупреждение, например, за нарушение режима зоны таможенного контроля (ст. 16.5 КоАП РФ); административного штраф, за незаконное перемещение через таможенную границу Таможенного союза товаров и (или) транспортных средств международной перевозки (ст. 16.1 КоАП РФ); конфискацию предметов административного правонарушения за несоблюдение установленных международными договорами государств - членов Таможенного союза, решениями Комиссии Таможенного союза и нормативными правовыми актами Российской Федерации, изданными в соответствии с международными договорами государств - членов Таможенного союза, мер нетарифного регулирования при ввозе товаров на таможенную территорию Таможенного союза или в Российскую Федерацию и (или) при вывозе товаров с таможенной территории Таможенного союза или из Российской Федерации (п.2. ст. 16.3 КоАП РФ).

Административно-правовое регулирование применения методов убеждения и принуждения в экономической деятельности таможенных органов соответствует принципам законности, ответственности, эффективности этой деятельности и способствует целям и назначению такой деятельности. Подсчитано, что в среднем, каждый служащий таможенных органов только в 2011 году обеспечил поступление в федеральный бюджет более 90 млн. рублей.

\section{Библиография}

1. Таможенный кодекс Таможенного союза;

2. Налоговый кодекс Российской Федерации. Часть первая;

3. Федеральный закон от 27 ноября 2010 г. № 311-Ф3 (ред. 06.12.2011) «О таможенном регулировании в Российской Федерации» //С3 РФ. - 2010.-№ 48.-Ст. 6252;

4. Федеральный закон от 04 мая 2011 № 99-Ф3 «О лицензировании отдельных видов деятельности»// СЗРФ, 2011.-№ 19.-Ст. 2716; 
5. Постановлением Правительства от 21 ноября 2011 № 957 «Об организации лицензирования отдельных видов деятельности»// С3 РФ, 2011.-№ 48.-Ст. 6931;

6. Постановление Правительства РФ от 26 июля 2006 г. № 459 «О Федеральной таможенной службе» (ред. 31.01.2012) // СЗ РФ.-2006.-№ 32.-Ст. 3569.

7. Райзберг Б.А., Лозовский Л.Ш., Стародубцева Е.Б.Современный экономический словарь. М.: ИНФРА-М, 2006;

8. Яковлев В.Ф. Гражданский кодекс и государство//Вестник ВАС РФ, 1997. № 6.-С. 133.

9. Справочная правовая база СПС КонсультантПлюс;

10. http://www.customs.ru

11. Костенников М.В. К вопросу о некоторых актуальных проблемах административного права // NB: Административное право и практика администрирования. - 2013. - 4. - С. 71 - 95. URL: http://www.e-notabene.ru/al/ article_8840.html

\section{References}

1. Tamozhennyi kodeks Tamozhennogo soyuza;

2. Nalogovyi kodeks Rossiiskoi Federatsii. Chast' pervaya;

3. Federal'nyi zakon ot 27 noyabrya 2010 g. № 311-FZ (red. 06.12.2011) «O tamozhennom regulirovanii v Rossiiskoi Federatsii» //SZ RF. - 2010.-№ 48.-St. 6252;

4. Federal'nyi zakon ot 04 maya 2011 № 99-FZ «O litsenzirovanii otdel'nykh vidov deyatel'nosti»// SZRF, 2011.-No 19.St. 2716;

5. Postanovleniem Pravitel'stva ot 21 noyabrya 2011 № 957 «Ob organizatsii litsenzirovaniya otdel'nykh vidov deyatel'nosti»// SZ RF, 2011.-№ 48.-St. 6931;

6. Postanovlenie Pravitel'stva RF ot 26 iyulya 2006 g. № 459 «O Federal'noi tamozhennoi sluzhbe» (red. 31.01.2012) // SZ RF.-2006.-№ 32.-St. 3569.

7. Raizberg B.A., Lozovskii L.Sh., Starodubtseva E.B.Sovremennyi ekonomicheskii slovar'. M.: INFRA-M, 2006;

8. Yakovlev V.F. Grazhdanskii kodeks i gosudarstvo//Vestnik VAS RF, 1997. № 6.-S. 133.

9. Spravochnaya pravovaya baza SPS Konsul'tantPlyus;

10. http://www.customs.ru

11. Kostennikov M.V. K voprosu o nekotorykh aktual'nykh problemakh administrativnogo prava // NB: Administrativnoe pravo i praktika administrirovaniya. - 2013. - 4. - C. 71 - 95. URL: http://www.e-notabene.ru/al/article_8840.html 